\title{
METODE INTEGRATED GENERALIZED AUTOREGRESSIVE CONDITIONAL HETEROSCEDASTICITY (IGARCH) UNTUK MEMODELKAN HARGA GABAH DUNIA (INTEGRATED GENERALIZED AUTOREGRESSIVE CONDITIONAL HETEROSCEDASTICITY TO CAPTURE THE WORLD'S GRAIN PRICE)
}

\author{
Aninda Firdayati Sidik ${ }^{1}$, Jamaliatul Badriyah ${ }^{2}$ \\ ${ }^{1}$ Universitas Negeri Malang, aniinaninda@gmail.com \\ ${ }^{2}$ Universitas Negeri Malang, jamailatul.badriyah.mat@um.ac.id
}

\begin{abstract}
Abstrak
Gabah merupakan komoditas yang strategis untuk menentukan volume beras. Harga gabah yang cenderung fluktuatif menyebabkan adanya ketidak konsistenan pada volatilitas dan heteroskedastisitas pada data. Oleh karena itu, untuk meramalkan harga gabah dibutuhkan suatu metode yang dapat menjelaskan heteroskedastisitas pada data. Pada penelitian ini akan digunakan IGARCH untuk meramalkan harga gabah. Dari hasil peramalan, didapatkan bahwa model yang cocok untuk meramalkan harga gabah adalah $\operatorname{ARIMA}(0,0,1)-\operatorname{IGARCH}(2,3)$. Serta hasil peramalan menunjukkan adanya penurunan pada harga gabah selama sepuluh hari berikutnya.
\end{abstract}

Kata kunci: Deret waktu, Heteroskedastisitas, IGARCH, Peramalan

\begin{abstract}
Grain is a strategic comodity which determines the rice's volume. The fluctuativity in grain price causes the unconsistencity in the volatility and heteroscedasticity in the data. Thus, to forecast the grain price, we need a method which has an ability to capture the heteroscedasticity in the data. In this research, we use IGARCH to forecast the grain price. The result shows that the best IGARCH models to capture the grain price is $\operatorname{ARIMA}(0,0,1)-\operatorname{IGARCH}(2,3)$. Moreover, it is shown from the result that the grain price will experience a gradually decrease in the next ten days.
\end{abstract}

Keywords: Time Series, Heteroscedasticity, IGARCH, Forecasting.

\section{PENDAHULUAN}

Gabah merupakan komoditas strategis yang menentukan volume beras. Pasar gabah sangat dipengaruhi oleh sifat produksi (panen) usaha tani padi, sifat produk gabah, dan karakteristik petani. Harga gabah yang cenderung fluktuatif sehingga menyebabkan adanya ketidakkonstanan pada volatilitas. Hal ini menjadikan asumsi data menjadi heteroskedastis. Oleh karena itu, diperlukan suatu metode yang mampu menjelaskan masalah heteroskedastisitas pada data.

Model GARCH, dalam perkembangannya (Engle, 1982) memperkenalkan model Autoregressive Conditional Heteroscedastic (ARCH) untuk melihat model heterokedastisitas dengan melihat hubungan variansi bersyarat dari kombinasi linier kuadrat di masa lalu. Selanjutnya Bollerslev (1986) memperkenalkan model Generalized Autoregressive Conditional Heteroscedastic (GARCH) 
sebagai pengembangan dari model ARCH.

Model GARCH(p,q) merupakan model yang varian residual $\sigma^{2}$ tidak hanya dipengaruhi oleh residual periode lalu $e_{t-1}^{2}$ tetapi juga varian residual periode lalu $\sigma_{t-1}^{2}$. Bentuk umum model GARCH(p,q) (Tsay, 2002):

$$
\sigma_{t}^{2}=a_{0}+\sum_{j=1}^{p} \beta_{j} \sigma_{t-j}^{2}+\sum_{i=1}^{q} \alpha_{i} e_{t-1}^{2}
$$

Dimana $a_{0}>0, a_{i} \geq 0, \beta_{j} \geq 0$ agar $\sigma_{t}^{2}>0$ dan $\sum_{j=1}^{p} \sum_{i=1}^{q}\left(\alpha_{i}+\beta_{j}\right)<1$ agar model bersifat stasioner.

ARCH dan GARCH merupakan model runtun waktu yang dapat menjelaskan heterokedastisitas pada data. Akan tetapi, model ARCH-GARCH tidak selalu dapat menangkap secara penuh adanya unit root dengan frekuensi tinggi. Francq \& Zakoïan (2011) menemukan model Integrated Generalized Autoregressive Conditional Heteroskedasticity (IGARCH) yang dapat menutupi kelemahan model GARCH.

Engle (2001) dan Bollerslev (1986) menyatakan Integrated GARCH $(\operatorname{IGARCH}(\mathrm{p}, \mathrm{q}))$ adalah tipe khusus dari model GARCH $(\mathrm{p}, \mathrm{q})$. Model ini cukup efektif digunakan karena sebagian besar model data deret waktu keuangan memiliki koefisien ragam yang jumlahnya sama dengan satu. Model IGARCH ketika $a_{i}+b_{j}=1$, dimana $a_{i}$ adalah koefisien residual dan $b_{j}$ adalah koefisien ragam residual yang bertindak seperti proses akar unit sehingga akan tetap menjaga keutuhan model ragam bersyarat tersebut. Integrated Generalized Autoregressive Conditional Heteroskedasticity (IGARCH) digunakan apabila dalam model GARCH terdapat akar unit. Pemodelan IGARCH menurut Francq \& Zakoïan (2010):

$$
\begin{aligned}
& \sigma_{t}^{2}=\sum_{i=1}^{p} \alpha_{i} e_{t-i}^{2}+\sum_{j=1}^{q} \beta_{j} \sigma_{t-j}^{2} \\
& \operatorname{dimana} \sum_{i=1}^{p} \alpha_{i}+\sum_{j=1}^{q} \beta_{j}=1
\end{aligned}
$$

Perbedaan utama antara IGARCH dan GARCH adalah dalam IGARCH konstanta $\alpha_{0}$ dihilangkan dan yang paling penting dari IGARCH adalah jumlah koefisien antara ARCH dan GARCH sama dengan satu. Oleh karena itu, tujuan dari penelitian ini adalah membahas penggunaan IGARCH untuk mengatasi masalah volatilitas residual dan meramalkan harga gabah dunia.

\section{METODE}

Data yang digunakan adalah data sekunder yang diambil dari data harga gabah dunia pada periode 2 Januari 2014 sampai 31 Januari 2017 dengan jumlah observasi 777 hari. Data tersebut diambil dari closing price pada situs id.investing.com dan diakses pada tanggal 1 Februari 2017. 


\section{HASIL DAN PEMBAHASAN}

Deskripsi data harga gabah dunia disarikan dalam Tabel 1. Dari tabel tersebut terlihat bahwa harga gabah terendah adalah 9.195 sedangkan harga gabah tertinggi 16.045 dan harga gabah rata-rata 11.731.

Tabel 1. Deskripsi data

\begin{tabular}{llllll}
\hline Nilai min. & Nilai Maks. & Mean & Range & St. Deviasi & Varian \\
\hline 9195 & 16045 & 11731 & 6850 & 1893 & 3584302 \\
\hline
\end{tabular}

Uji kestasioneran data terhadap rata-rata dapat diduga menggunakan metode Augmented Dickey-Fuller (ADF) dan uji kestasioneran terhadap varian dapat diduga menggunakan Transformasi Box-Cox. Hasil uji unit root dengan metode Augmented Dickey-Fuller (ADF) dapat dilihat pada Tabel 2.

Tabel 2. Uji ADF Data Harga Gabah

\begin{tabular}{ccc}
\hline & t-Statistik & Probabilitas \\
\hline Statistik Uji ADF & -1.878694 & 0.3452 \\
Nilai Kritis: level 1\% & -3.438562 & \\
level 5\% & -2.865054 & \\
level 10\% & -2.568696 & \\
\hline
\end{tabular}

Dari Tabel tersebut diperoleh nilai probabilitas ADF data harga gabah dunia sebesar 0.3425 . Nilai tersebut lebih dari taraf signifikansi 5\% sehingga $H_{0}$ diterima yang berarti data harga gabah dunia tidak stasioner terhadap ratarata.

Karena data harga gabah tidak stasioner terhadap rata-rata, maka dilakukan differencing orde pertama. Data harga gabah dunia yang telah didifferencing orde pertama perlu diuji kestasioneran datanya dengan menguji unit root menggunakan metode Augmented Dickey-Fuller (ADF) dan hasilnya dapat dilihat pada Tabel 3 .

Tabel 3. Uji ADF Data Diff Harga Gabah

\begin{tabular}{cll}
\hline & t-Statistik & Probabilitas \\
\hline Statistik Uji ADF & -31.22914 & 0.0000 \\
Nilai Kritis: level 1\% & -3.438562 & \\
level 5\% & -2.865054 & \\
level 10\% & -2.568696 & \\
\hline
\end{tabular}

Dari Tabel 3 diperoleh nilai probabilitas ADF data harga gabah dunia sebesar 0.000 . Nilai tersebut kurang dari taraf signifikansi $5 \%$ sehingga $H_{0}$ ditolak yang berarti data harga gabah dunia sudah stasioner terhadap rata-rata.

Selanjutnya data dikatakan stasioner terhadap varian apabila nilai lambda hasil transformasi Box-Cox bernilai \pm 1 . Hasil transformasi Box-Cox dapat dilihat pada Gambar 1. Dari Gambar 1 diperoleh rounded value sebesar 1.00, artinya data tersebut telah stasioner terhadap varian. 


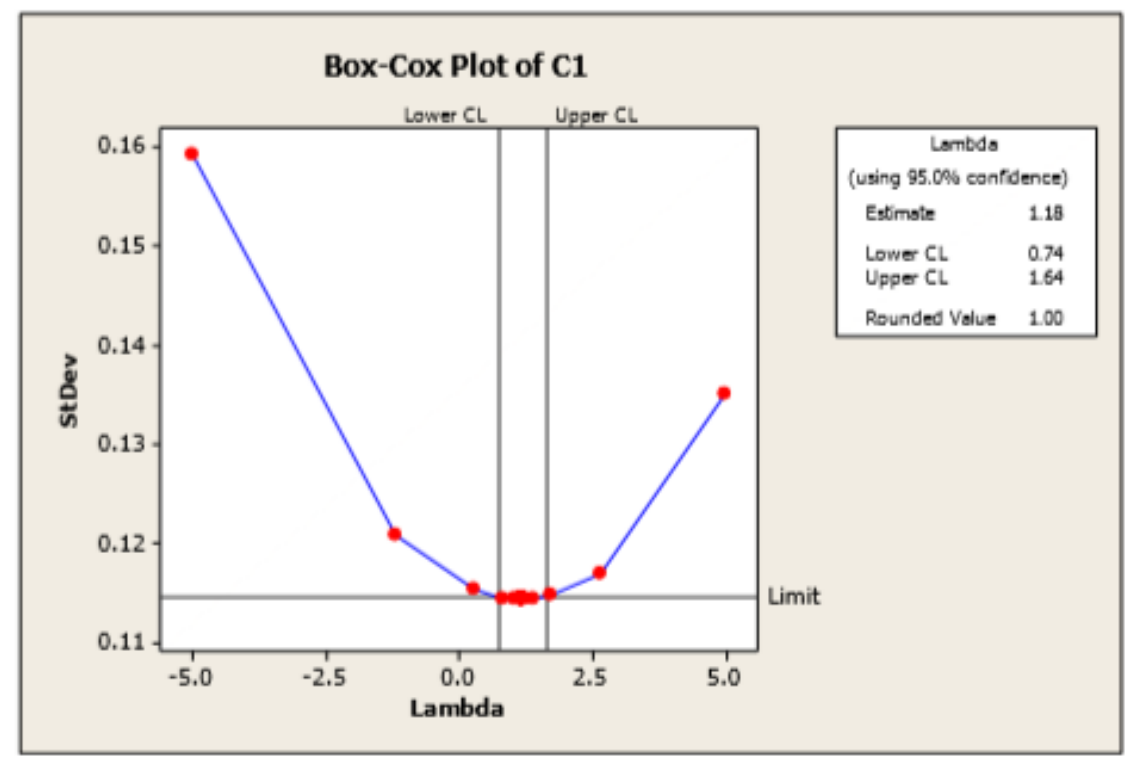

Gambar 1. Transformasi Box-Cox Data Diff Harga Gabah

Kemudian identifikasi model AR dan MA dari data dilakukan dengan melihat grafik nilai ACF dan PACF pada berbagai lag. Grafik nilai PACF dan ACF dapat dilihat pada Gambar 2 dan Gambar 3.

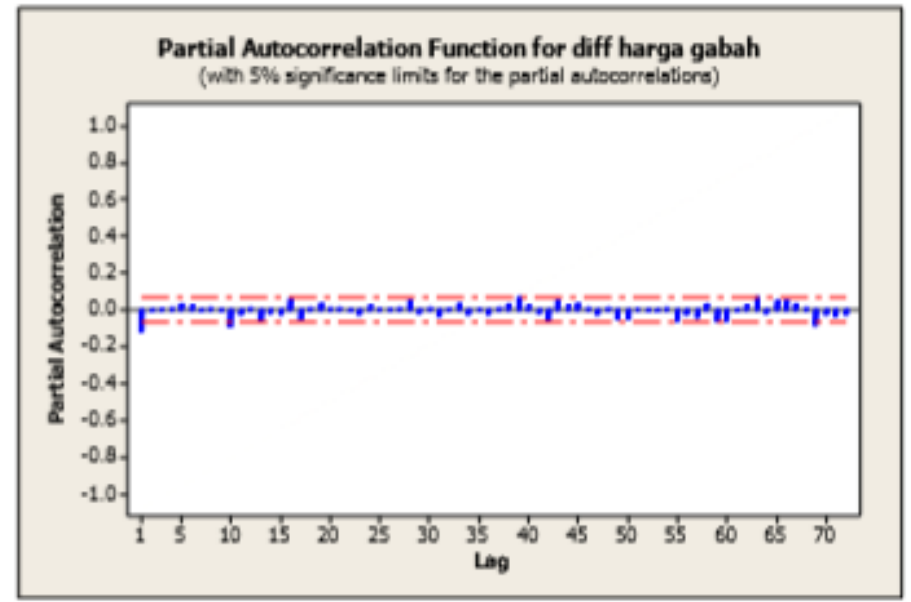

Gambar 2. PACF Diff Harga Gabah

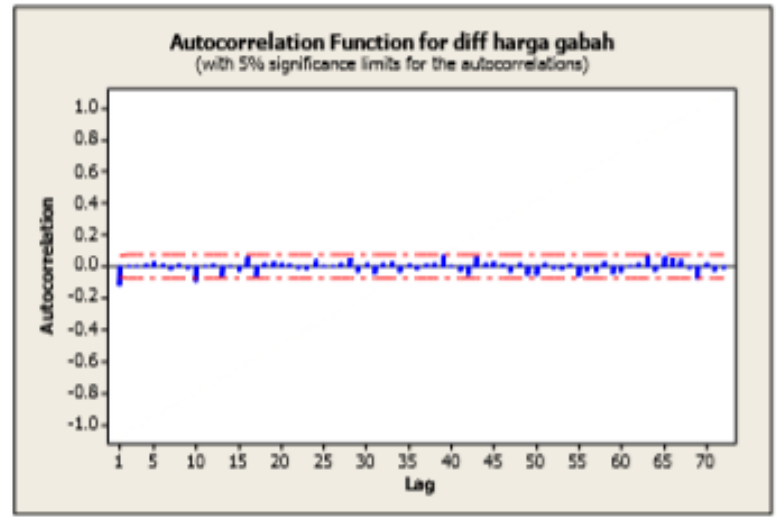

Gambar 3. ACF Diff Harga Gabah 
Dari gambar 2 dan 3, PACF dan ACF menunjukkan bahwa terdapat satu garis yang memotong garis batas yaitu pada lag pertama. Sehingga model ARIMA yang dapat diidentifikasikan untuk data harga gabah yang telah didifferencing adalah ARIMA $(1,0,1)$. Selain itu, trial and error untuk model ARIMA yang dapat digunakan $\operatorname{ARIMA}(1,0,0), \operatorname{ARIMA}(0,0,1)$, dan $\operatorname{ARIMA}(1,0,1)$.

Setelah diketahui model tentatif, langkah selanjutnya adalah estimasi model ARIMA. Estimasi dari model-model ARIMA dapat dilihat pada Tabel 4. Dari Tabel 4, parameter yang signifikan terdapat pada model $\operatorname{ARIMA}(1,0,0)$ dan ARIMA(0,0,1). Pada model ARIMA(0,0,1), model tersebut memiliki nilai AIC sebesar-0.571982 yang merupakan nilai terkecil dibandingkan dengan model lainnya. Jadi, model terbaik yang dipilih berdasarkan nilai AIC yang terkecil adalah model ARIMA $(0,0,1)$.

Tabel 4. Estimasi Parameter Model ARIMA

\begin{tabular}{|c|c|c|c|c|}
\hline \multirow[t]{2}{*}{ Model } & \multirow{2}{*}{$\begin{array}{l}\text { Uji Signifikan } \\
\text { Parameter }\end{array}$} & \multirow[t]{2}{*}{ AIC } & \multicolumn{2}{|c|}{ Uji Diagnostik Mode } \\
\hline & & & $\begin{array}{l}\text { Uji Normalitas } \\
\text { Residual }\end{array}$ & $\begin{array}{c}\text { Uji Kebebasan } \\
\text { Residual }\end{array}$ \\
\hline $\operatorname{ARIMA}(\mathbf{1 , 0 , 0 )}$ & Signifikan & -0.570544 & $\begin{array}{c}\text { Tidak } \\
\text { Memenuhi Uji }\end{array}$ & Memenuhi Uji \\
\hline $\operatorname{ARIMA}(0,0,1)$ & Signifikan & -0.571982 & $\begin{array}{c}\text { Tidak } \\
\text { Memenuhi Uji }\end{array}$ & Memenuhi Uji \\
\hline $\operatorname{ARIMA}(\mathbf{1}, \mathbf{0 , 1})$ & Signifikan & -0.568112 & $\begin{array}{c}\text { Tidak } \\
\text { Memenuhi Uji }\end{array}$ & Memenuhi Uji \\
\hline
\end{tabular}

Selanjutnya uji ARCH-Lagrange Multiplier yang hasilnya dapat dilihat pada Tabel 5. Berdasarkan uji tersebut didapatkan nilai probabilitas Chi-Square 0,0000 yang berarti terdapat efek heteroskedastisitas atau efek ARCH.

Tabel 5. Uji Efek ARCH

\begin{tabular}{llll}
\hline $\boldsymbol{F}$-Statistik & $\mathbf{3 3 . 0 5 7 1 0}$ & Prob.F(1,772) & $\mathbf{0 . 0 0 0 0}$ \\
\hline Obs*R-squared & 31.78184 & Prob.Chi-Square(1) & 0.0000 \\
\hline
\end{tabular}

Kemudian estimasi parameter GARCH dapat dilihat pada tabel 6. Dari Tabel 6, semua parameter ARIMA $(0,0,1)$ tidak ada yang signifikan, tetapi untuk parameter GARCH $(1,1)$, GARCH $(1,2)$, dan GARCH $(2,3)$ menunjukkan parameter GARCH yang signifikan. Model GARCH $(2,3)$ adalah model yang memiliki nilai AIC yang paling kecil dibandingkan dengan model lain dari GARCH yang signifikan. 


\begin{tabular}{|c|c|c|c|c|}
\hline \multirow[b]{2}{*}{ No. } & \multirow[b]{2}{*}{ Model } & \multicolumn{2}{|c|}{ Signifikansi Parameter } & \multirow[b]{2}{*}{ AIC } \\
\hline & & ARIMA & GARCH & \\
\hline 1 & $\operatorname{ARIMA}(0,0,1)-\operatorname{GARCH}(1,1)$ & $\begin{array}{c}\text { Tidak } \\
\text { Signifikan }\end{array}$ & Signifikan & -0.728578 \\
\hline 2 & $\operatorname{ARIMA}(0,0,1)-\operatorname{GARCH}(1,2)$ & $\begin{array}{c}\text { Tidak } \\
\text { Signifikan }\end{array}$ & Signifikan & -0.731524 \\
\hline 3 & $\operatorname{ARIMA}(0,0,1)-\operatorname{GARCH}(1,3)$ & $\begin{array}{c}\text { Tidak } \\
\text { Signifikan }\end{array}$ & $\begin{array}{c}\text { Tidak } \\
\text { Signifikan }\end{array}$ & -0.728450 \\
\hline 4 & $\operatorname{ARIMA}(0,0,1)-\operatorname{GARCH}(2,1)$ & $\begin{array}{c}\text { Tidak } \\
\text { Signifikan }\end{array}$ & $\begin{array}{c}\text { Tidak } \\
\text { Signifikan }\end{array}$ & -0.726590 \\
\hline 5 & $\operatorname{ARIMA}(0,0,1)-\operatorname{GARCH}(2,2)$ & $\begin{array}{c}\text { Tidak } \\
\text { Signifikan }\end{array}$ & $\begin{array}{c}\text { Tidak } \\
\text { Signifikan }\end{array}$ & -0.729093 \\
\hline 6 & $\operatorname{ARIMA}(0,0,1)-\operatorname{GARCH}(2,3)$ & $\begin{array}{c}\text { Tidak } \\
\text { Signifikan }\end{array}$ & Signifikan & -0.747846 \\
\hline 7 & $\operatorname{ARIMA}(0,0,1)-\operatorname{GARCH}(3,1)$ & $\begin{array}{c}\text { Tidak } \\
\text { Signifikan }\end{array}$ & $\begin{array}{c}\text { Tidak } \\
\text { Signifikan }\end{array}$ & -0.724845 \\
\hline 8 & $\operatorname{ARIMA}(0,0,1)-\operatorname{GARCH}(3,2)$ & $\begin{array}{c}\text { Tidak } \\
\text { Signifikan }\end{array}$ & $\begin{array}{c}\text { Tidak } \\
\text { Signifikan }\end{array}$ & -0.727327 \\
\hline 9 & $\operatorname{ARIMA}(0,0,1)-\operatorname{GARCH}(3,3)$ & $\begin{array}{c}\text { Tidak } \\
\text { Signifikan }\end{array}$ & $\begin{array}{c}\text { Tidak } \\
\text { Signifikan }\end{array}$ & -0.724453 \\
\hline
\end{tabular}

Estimasi parameter model $\operatorname{ARIMA}(0,0,1)-\operatorname{GARCH}(2,3)$ dapat dilihat pada Tabel 7. Berdasarkan Tabel 7 koefisien ARCH dan GARCH jumlah semua koefisiennya sama dengan 1. Hal tersebut dapat dilihat dari koefisien $\alpha_{1}+\alpha_{2}+\beta_{1}+\beta_{2}+\beta_{3}=1$. Karena jumlah semua koefisien ARCH dan GARCH sama dengan 1 menunjukkan bahwa pada model tersebut terdapat akar unit. Oleh karena itu, perlu dilakukan pemodelan dengan menggunakan IGARCH.

Tabel 7.Estimasi Parameter ARIMA(0,0,1)-GARCH(2,3)

\begin{tabular}{ccccc}
\hline Model & Parameter & $\begin{array}{c}\text { Estimasi } \\
\text { Parameter }\end{array}$ & p-value & AIC \\
\hline ARIMA(0,0,1)- & $\theta_{1}$ & -0.017565 & 0.6476 & -0.747846 \\
GARCH(2,3 & $C$ & 0.000114 & 0.0000 & \\
& $\alpha_{1}$ & 0.092757 & 0.0000 & \\
$\alpha_{2}$ & -0.092710 & 0.0000 & \\
$\beta_{1}$ & 1.943818 & 0.0000 & \\
$\beta_{2}$ & -1.277183 & 0.0000 & \\
$\beta_{3}$ & 0.329837 & 0.0000 & \\
& & &
\end{tabular}


Hampir serupa dengan model GARCH, estimasi model IGARCH juga dilakukan dari IGARCH berorde 1 sampai berorde 3. Estimasi parameter model IGARCH disajikan pada Tabel 8.

Tabel 8. Estimasi Parameter IGARCH

\begin{tabular}{|c|c|c|c|c|}
\hline \multirow{2}{*}{ No. } & \multirow{2}{*}{ Model } & \multicolumn{2}{|c|}{ Signifikansi Parameter } & \multirow{2}{*}{ AIC } \\
\hline & & ARIMA & IGARCH & \\
\hline 1 & $\operatorname{ARIMA}(0,0,1)-\operatorname{IGARCH}(1,1)$ & $\begin{array}{c}\text { Tidak } \\
\text { Signifikan }\end{array}$ & Signifikan & -0.648628 \\
\hline 2 & $\operatorname{ARIMA}(0,0,1)-\operatorname{IGARCH}(1,2)$ & $\begin{array}{c}\text { Tidak } \\
\text { Signifikan }\end{array}$ & Signifikan & -0.653570 \\
\hline 3 & $\operatorname{ARIMA}(0,0,1)-\operatorname{IGARCH}(1,3)$ & $\begin{array}{c}\text { Tidak } \\
\text { Signifikan }\end{array}$ & Signifikan & -0.652944 \\
\hline 4 & $\operatorname{ARIMA}(0,0,1)-\operatorname{IGARCH}(2,1)$ & $\begin{array}{c}\text { Tidak } \\
\text { Signifikan }\end{array}$ & Signifikan & -0.650522 \\
\hline 5 & $\operatorname{ARIMA}(0,0,1)-\operatorname{IGARCH}(2,2)$ & $\begin{array}{c}\text { Tidak } \\
\text { Signifikan }\end{array}$ & $\begin{array}{c}\text { Tidak } \\
\text { Signifikan }\end{array}$ & -0.652489 \\
\hline 6 & $\operatorname{ARIMA}(0,0,1)-\operatorname{IGARCH}(2,3)$ & Signifikan & Signifikan & -0.653817 \\
\hline 7 & $\operatorname{ARIMA}(0,0,1)-\operatorname{IGARCH}(3,1)$ & $\begin{array}{c}\text { Tidak } \\
\text { Signifikan }\end{array}$ & $\begin{array}{c}\text { Tidak } \\
\text { Signifikan }\end{array}$ & -0.647984 \\
\hline 8 & $\operatorname{ARIMA}(0,0,1)-\operatorname{IGARCH}(3,2)$ & $\begin{array}{c}\text { Tidak } \\
\text { Signifikan }\end{array}$ & $\begin{array}{c}\text { Tidak } \\
\text { Signifikan }\end{array}$ & -0.651152 \\
\hline 9 & $\operatorname{ARIMA}(0,0,1)-\operatorname{IGARCH}(3,3)$ & $\begin{array}{c}\text { Tidak } \\
\text { Signifikan }\end{array}$ & Signifikan & -0.661106 \\
\hline
\end{tabular}

Dari Tabel 8, model ARIMA dan IGARCH yang signifikan hanya pada model 6 yaitu model ARIMA $(0,0,1)$-IGARCH $(2,3)$. Estimasi parameter model ARIMA(0,0,1) - IGARCH $(2,3)$ dapat dilihat pada Tabel 9. Berdasarkan Tabel 9 diperoleh persamaan untuk model $\operatorname{ARIMA}(0,0,1)-\operatorname{IGARCH}(2,3)$ adalah $Z_{t}=\varepsilon_{t}+0.0746 \varepsilon_{t-1}$ dengan $\sigma_{t}^{2}=0.0883 e_{t-1}+0.0739 e_{t-2}+0.1129 \sigma_{t-1}-0.1477 \sigma_{t-2}+0.8725 \sigma_{t-3}$

Tabel 9. Estimasi Parameter ARIMA(0,0,1)-IGARCH(2,3)

\begin{tabular}{ccccc}
\hline Model & Parameter & Estimasi Parameter & p-value & AIC \\
\hline ARIMA(0,0,1)- & $\theta_{1}$ & -0.074615 & 0.0173 & -0.653817 \\
IGARCH(2,3) & $\alpha_{1}$ & 0.088310 & 0.0000 & \\
& $\alpha_{2}$ & 0.073934 & 0.0000 & \\
$\beta_{1}$ & 0.112917 & 0.0000 & \\
$\beta_{2}$ & -0.147661 & 0.0000 & \\
$\beta_{3}$ & 0.872500 & 0.0000 & \\
\hline
\end{tabular}


Kemudian model IGARCH terbaik dievaluasi dengan uji normalitas residual, uji keacakan residual, dan uji efek ARCH. Hasil dari uji tersebut dapat dilihat pada Tabel 10. Berdasarkan Tabel 10 uji normalitas residual tidak terpenuhi, hal tersebut menunjukkan bahwa ketidaknormalan mengindikasikan bahwa data memiliki volatilitas (varians) yang acak. Uji keacakan residual terpenuhi yang berarti residual pada model sudah bersifat acak. Sedangkan untuk uji efek ARCH tidak terpenuhi yang menunjukkan sudah tidak ada lagi efek ARCH pada data.

Tabel 10. Hasil Uji Kelayakan Model

\begin{tabular}{lll}
\hline Normalitas Residual & Keacakan Residual & Efek ARCH \\
\hline Tidak Terpenuhi & Terpenuhi & Tidak Terpenuhi \\
\hline
\end{tabular}

\section{Peramalan}

Peramalan data harga gabah dunia untuk sepuluh hari kedepan dapat dilihat pada Tabel 11.

Tabel 11. Peramalan Harga Gabah Dunia

\begin{tabular}{ll}
\hline Hari ke- & Harga Gabah Dunia \\
\hline $\mathbf{7 7 8}$ & 13.23977 \\
$\mathbf{7 7 9}$ & 13.23650 \\
$\mathbf{7 8 0}$ & 13.23324 \\
$\mathbf{7 8 1}$ & 13.22998 \\
$\mathbf{7 8 2}$ & 13.22671 \\
$\mathbf{7 8 3}$ & 13.22345 \\
$\mathbf{7 8 4}$ & 13.22019 \\
$\mathbf{7 8 5}$ & 13.21693 \\
$\mathbf{7 8 6}$ & 13.21366 \\
$\mathbf{7 8 7}$ & 13.21040 \\
\hline
\end{tabular}

Berdasarkan Tabel 11, hasil peramalan harga gabah dunia selama sepuluh hari berikutnya menunjukkan akan mengalami penurunan secara berkala.

\section{KESIMPULAN DAN SARAN}

Berdasarkan hasil analisis data dan pembahasan pada bab sebelumnya, maka dapat diperoleh kesimpulan bahwa model IGARCH terbaik untuk data harga gabah dunia adalah ARIMA(0,0,1)-IGARCH(2,3) dengan persamaan:

$$
\begin{aligned}
& Z_{t}=\varepsilon_{t}+0.0746 \varepsilon_{t-1} \\
& \text { dengan } \\
& \sigma_{t}^{2}=0.0883 e_{t-1}+0.0739 e_{t-2}+0.1129 \sigma_{t-1}-0.1477 \sigma_{t-2}+0.8725 \sigma_{t-3}
\end{aligned}
$$

Hasil peramalan gabah selama sepuluh hari berikutnya menunjukkan adanya penurunan harga secara berkala. Untuk penelitian berikutnya, disarankan untuk mencoba menggunakan metode yang lain untuk meramalkan harga gabah dan mengambil lebih banyak data. 
DAFTAR RUJUKAN

Bollerslev, T. (1986). Generalized autoregressive conditional heteroscedasticity. Journal of Econometrics, 31, 307-327.

Engle, R. (2001). GARCH 101: the use of ARCH/GARCH models in applied econometrics. Journal of Economic Perspectives, 15(4), 157-168. https://doi.org/10.1257/jep.15.4.157

Engle, R. F. (1982). Autoregressive conditional heteroscedasticity with estimates of the variance of united kingdom inflation. Econometrica, 50(4), 987. https://doi.org/10.2307/1912773

Francq, C., \& Zakoïan, J. M. (2011). GARCH models: structure, statistical inference and financial applications. John Wiley \& Sons. https://doi.org/10.1002/9780470670057

Tsay, R. S. (2002). Analysis of financial time series. John WIley and Sons (Vol. 44). Canada. https://doi.org/10.1198/tech.2006.s405 